Research Article

\title{
Dying in the Intensive Care Unit (ICU): A Retrospective Descriptive Analysis of Deaths in the ICU in a Communal Tertiary Hospital in Germany
}

\author{
Esma Ay, ${ }^{1}$ Markus. A. Weigand, ${ }^{2}$ Rainer Röhrig, ${ }^{3}$ and Marco Gruss $\mathbb{C}^{1}$ \\ ${ }^{1}$ Department of Anaesthesiology, Intensive Care Medicine and Pain Therapy, Klinikum Hanau GmbH, Leimenstrasse 20, \\ Hanau D-63450, Germany \\ ${ }^{2}$ Department of Anaesthesiology, Heidelberg University Hospital, Im Neuenheimer Feld 110, Heidelberg D-69120, Germany \\ ${ }^{3}$ Department of Medical Informatics, University Hospital RWTH Aachen, Aachen, Germany
}

Correspondence should be addressed to Marco Gruss; marco.gruss@web.de

Received 19 October 2019; Revised 17 January 2020; Accepted 22 January 2020; Published 1 March 2020

Academic Editor: Fabrizio Monaco

Copyright (C) 2020 Esma Ay et al. This is an open access article distributed under the Creative Commons Attribution License, which permits unrestricted use, distribution, and reproduction in any medium, provided the original work is properly cited.

\begin{abstract}
Background. Modern intensive care methods led to an increased survival of critically ill patients over the last decades. But an unreflected application of modern intensive care measures might lead to prolonged treatment for incurable diseases, and an inadaequate or too aggressive therapy can prolong the dying process of patients. In this study, we analysed end-of-life decisions regarding withholding and withdrawal of intensive care measures in a German intensive care unit (ICU) of a communal tertiary hospital. Methods. Patient datasets of all adult patients dying in an ICU or an intermediate care unit (IMC) in a tertiary communal hospital (Klinikum Hanau, Germany) between 01.01.2011 and 31.12.2012 were analysed for withholding and withdrawal of intensive care measures. Results. During the two-year period, 1317 adult patients died in Klinikum Hanau. Of these, 489 (37\%) died either in an ICU/IMC unit. The majority of those deceased patients $(n=427,87 \%)$ was 60 years or older. In $306(62 \%)$ of 489 patients, at least one life-sustaining measure was withheld or withdrawn. In 297 (61\%) of 489 patients dying in ICU/IMC, any type of therapy was withheld, and in 139 patients (28\%), any type of therapy was withdrawn. Mostly, cardiopulmonary resuscitation $(n=222)$, invasive $(n=121)$ and noninvasive $(n=40)$ ventilation followed by renal replacement therapy $(n=71)$ and catecholamine therapy $(n=66)$ were withheld. More invasive measures as ventilation or renal replacement therapy were withdrawn in 18 and 22 patients only. After withholding/withdrawal of therapy, most patients died within two days. More than $20 \%$ of patients dying in ICU/IMC did not have an analgesic medication. Conclusions. About one-third of patients dying in the hospital died in ICU/IMC. At least one life-sustaining therapy was limited/withdrawn in more than $60 \%$ of those patients. Withholding of a therapy was more common than active therapy withdrawal. Ventilation and renal replacement therapy were withdrawn in less than $5 \%$ of patients, respectively.
\end{abstract}

\section{Introduction}

The developments in modern medicine and especially in intensive care medicine after the Second World War led to an increased survival of critically ill patients. Over the last decades, there was an increased demand for intensive care unit (ICU) beds and an increasing number of hospitalised patients admitted to an intensive care unit during their hospital stay [1]. While more and more people survive acute critical situations, the developments in the organ support can lead to a state called "chronic critical illness" [2]. Because people are getting older and older, it can be expected that much more patients will need intensive care support during their hospital stay. In Germany, with an overall population of about 80 million people in $2014,27 \% / 6 \%$ of people were $65 / 80$ years or older, and it is expected that these fractions will increase to $38 \%$ and $13 \%$ in 2050 , respectively [3]. The numbers for the European Union are very similar [3]. An unreflected application of intensive care measures might lead to prolonged treatment for incurable diseases, and an inadequate or too aggressive therapy can prolong the dying process $[4,5]$. Due to the increasing number of patients dying 
in ICUs [1], there has been a lot of discussion about end-oflife decisions in intensive care units and how much and what intensity of care is in patient's best interest [4, 6-13]. Nowadays, withholding or even withdrawal of intensive care measures is a common practice in many ICUs, and several intensive care medicine societies have pointed out recommendations regarding end-of-life decisions [14-17].

Several studies investigated end-of-life decisions in different countries and different regions of the world. Similarities but also great variabilities in withholding and withdrawal practices have been described depending on socioeconomic, cultural, and religious background [1, 18-21].

Whereas most studies investigating end-of-life decisions focused on university hospitals [22, 23], there are less data about therapy withholding or withdrawal in community or teaching hospitals [24]. In Germany, there is only limited knowledge about the place of death and almost no data about where and especially under what circumstances patients are dying in hospitals [25].

In this study, we explored withholding and withdrawal of life-sustaining therapy in an 750-bed tertiary community and teaching hospital in detail by retrospective analysis of all patients dying in an ICU or intermediate care unit (IMC) in 2011 or 2012.

\section{Materials and Methods}

In this retrospective explorative study, we looked at end-oflife practices in adult patients who died in Klinikum Hanau, a communal German tertiary hospital with $\sim 750$ beds including 20 ICU and 16 IMC beds. Ethical approval was given before analysing data by the Landesärztekammer Hessen (FF $131 / 2013,23.01 .2014)$. We analysed charts of adult patients who died in an ICU or an IMC between 01.01.2011 and 31.12.2012 regarding any withholding or withdrawal of lifesustaining therapies. Originally, patients who died in 2010 were planned to be analysed but had to be excluded because patients' charts were archived in hardcopy form at an external location and therefore could not be looked at in an acceptable time course.

Patient charts of patients who died in 2011 or 2012 were archived in an electronic form. Any chart of these patients was looked at and analysed for patients' master data, date and time of admission to hospital and last admission to ICU, date and time of death, existence of an advance directive, life-sustaining measures during time of death, and if and which measures of life-sustaining therapy were withheld or withdrawn. Therapy was defined as withheldif decision was made not to start or to increase at least one life-sustaining intervention [19] and defined as withdrawn if decision was made to actively stop a life-sustaining intervention presently being given [19]. All 2011/2012 patients' charts were analysed by one investigator (E. A.), double-checked by the second investigator (M. G.), and discussed until an agreement was achieved. Only cases with clear documentation or unambiguous hints for withholding or withdrawal, e.g., stop of catecholamine infusion prior to death, were classified as withheld or withdrawn. All other cases were classified as negative. If there was no clear documentation regarding withholding of therapy but this could be reasoned by indirect hints in the patient's chart, it was classified as "not explicitly mentioned."

As far as possible, data were extracted from the hospital information system $\left(\mathrm{SAP}^{\circledR}{ }^{\circledR}\right.$, SAP Deutschland SE and Co. KG, Germany). The time interval from last admission on IMC/ICU until death was calculated, and the time interval from either withholding or withdrawal of therapy until death was estimated as exact as possible and classified in daily intervals. A more exact definition of the withholding/ withdrawal "time point" was not possible mainly due to paper-based documentation. The patient's main medical problem was classified according to the main classification in the German diagnosis-related group (DRG) system. All drugs not belonging to catecholamines, analgesics/sedatives, antibiotics, or feeding/nutrition were classified as "other drugs."

Graded or nominal classified variables are shown in absolute and relative frequency. Correlations data were analysed in cross tables by Chi-square and exact Fisher's test. Most variables were analysed descriptively by mean, median, and standard deviation. Differences between two groups (e.g., two groups of different ages) were tested by $t$-test or variance analysis, if more than two groups were compared. SPSS ${ }^{\circledR}$, Origin ${ }^{\circledR}$, and $\mathrm{R}^{\circledR}$ were used for data analysis.

\section{Results}

From January 2011 to December 2012, 1325 patients died in our hospital. Eight patients under 18 years old were excluded. From the remaining 1317 patients, 541 died either in an ICU or an IMC (Figure 1). We excluded 52 patients in most cases because they were formally classified as dying in an ICU/IMC but either died in the emergency room/operating room or reached the ICU under cardiopulmonary resuscitation (CPR). Finally, 489 data sheets of patients dying in an ICU/IMC in 2011 (267 patients) or in 2012 (222 patients) were analysed (Figure 1).

Patients' characteristics are shown in Table 1. About 70\% $(n=352)$ of patients dying in an ICU/IMC in our hospital were older than 70 years. Most patients died in medical ICU/ IMC, and most were treated because of cardiopulmonary problems. One patient labelled as pediatric was a 20 -year-old disabled patient with a long medical history and treated for severe pneumonia in the anaesthetic/interdisciplinary ICU. Because declaration of religious affiliation in Germany is not mandatory, we could not extract this information from the data in many cases. Main diagnosis-related groups (DRG) of patients are shown in Table 1. Some patients are labelled as "intensive complex treatment" because the complexity of the intensive care treatment triggered a special reimbursement independent from the original medical problem. The cause of death as extracted from the official death certificate was assigned as cardial or pulmonary in almost half the patients followed by gastrointestinal causes or malignancies. Only few patients were classified as "died due to sepsis" because the cause of death was related to the main organ system; e.g., severe sepsis due to pneumonia is classified as pulmonary (Table 1). Time of death is distributed almost equally over 


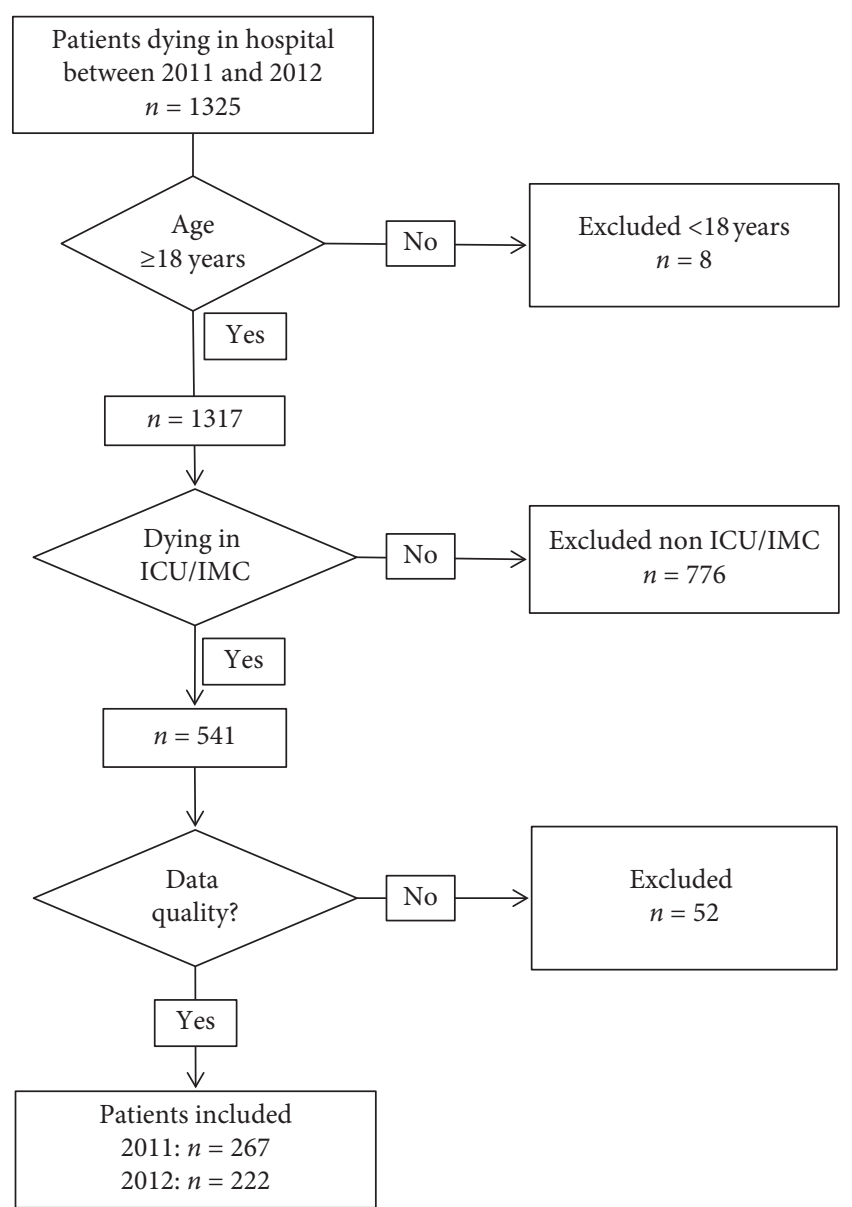

FIGURE 1: Selection of patients for data analysis. $N=$ number of patients; $y=$ years; 52 patients were excluded after analysing data because in most cases they were formally classified as "dying in ICU/IMC" but died either outside the ICU/IMC or, e.g., under CPR while admitted on ICU/IMC.

time of the day and days of the week (Table 1). Only 57 patients (12\%) had an advance directive. More than $80 \%$ of patients $(n=409)$ were less than 10 days in the ICU/IMC before they died, and almost 95\% $(n=461)$ of patients died within less than 20 days in ICU/IMC. Most patients $(75 \%$, $n=372$ ) were ventilated less than 100 hours before they died.

Table 2 measures at end-of-life versus sex, age and advance directive.

The different therapy measures at the end-of-life are shown in Table 2 . About $60 \%$ of patients were ventilated, and about half of them had catecholamine therapy, received antibiotics, and were fed enterally or parenterally. Around $20 \%$ died under CPR or had CPR just before their death. Almost $80 \%$ received any kind of analgesia, and $37 \%$ got any kind of sedation drugs.

In about $60 \%$ of patients $(n=297)$, we found direct documentation or unambiguous hints for withholding of at least one life-sustaining measure (Table 3). In 45\% existed a written "do not resuscitate" order. Invasive ventilation (24.7\%), noninvasive ventilation (8.2\%), renal replacement therapy (14.5\%), catecholamines (13.5\%) and other drugs, or feeding components were withheldless often.
In contrast to 297 patients with therapy withholding, we found withdrawal of any component of life-sustaining therapy in only 139 patients $(=28.4 \%$, Table 4$)$. The fractions decreased from $22.9 \%$ for "other drugs" to $11.6 \%$ for catecholamine therapy, $10.4 \%$ for feeding, and in less than $5 \%$ of patients eitherrenal replacement therapy (4.5\%), noninvasive $(1.0 \%)$ or invasive ventilation $(2.7 \%)$ was actively reduced or stopped.

After therapy withholding, half of the patients died within one day, and about $70 \%$ of percents died within two days (Figure 2). When life-sustaining therapy was withdrawn, about $80 \%$ of patients died within one day, and more than $90 \%$ of patients died within two days.

Table 4 withdrawal of therapy versus sex, age and advance directive.

There was no relevant difference in the frequency of the different measures at end-of-life as well as in the frequency of withholding or withdrawal between male and female patients (Tables 2-4). By trend, in younger patients, invasive measures are used more often and limited less often. As an example, patients invasively ventilated were younger than patients those not $(70.5 \pm 13.0$ years vs. $77.6 \pm 11.6$ years, $p<0.05)$ as well as patients receiving catecholamine therapy $(71.1 \pm 12.8$ years vs. $76.3 \pm 12.5$ years, $p<0.05$ ) were younger than those who did not get catecholamines. In contrast, there was no difference in the age of patients receiving CPR or not before death $(71.7 \pm 13.0$ years vs. $74.3 \pm 12.8$ years, $p=0.95)$, and patients noninvasively ventilated were even older that patients who were not $(79.0 \pm 9.5$ years vs. $73.5 \pm 13.0$ years, $p<0.05)$. There was no obvious relationship between withdrawal and age, but there was hardly any withdrawal at all in patients younger than 40 years (Table 4 ). Patients with a documented withholding of therapy were older $(76.4 \pm 11.4$ years $)$ than patients without $(69.8 \pm 13.7$ years, $p<0.05$, Table 3$)$. In contrast, there was no difference in age between patients with $(73.9 \pm 12.4$ years $)$ or without $(73.8 \pm 13.1$ years; $p=0.97$, Table 4) withdrawal of therapy.

We did not see any obvious difference in the frequency of use of the different therapy measures in therapy-withholding or withdrawal in patients of religious affiliation (data not shown). However, in most patients, the religious background is unknown, and absolute numbers of Jehovah's witnesses, Muslims, or "other" religions are very small.

Only $11.7 \%$ of patients dying in ICU/IMC had an advanced directive (Table 2). Those patients were older $(80.1 \pm 8.1$ years, $n=57)$ than patients without one $(73.0 \pm 13.2$ years, $p<0.05, n=432)$. Patients with a written advance directive were less often ventilated invasively and had much less cardiopulmonary resuscitation (Table 2). By trend, therapy was more often limited and withdrawn when patients had an advance directive (Table 2).

\section{Discussion}

We investigated end-of-life decisions in adult ICU/IMC patients in an urban nonuniversity tertiary hospital. This is in contrast to multicenter evaluations like the ETHICUS study [19] or a large French study [26]. But in the ETHICUS study, only two German hospitals contributed data and both 
TABLE 1: Characteristics of patients dying in the ICU/IMC in 2011 and 2012. Numbers are shown as absolute numbers $n$ and percentage (\%) of all patients dying in ICU/IMC in 2011 and 2012.

\begin{tabular}{|c|c|c|c|}
\hline \multicolumn{2}{|c|}{ Patients' characteristics } & \multirow{3}{*}{$\begin{array}{c}n \\
266 \\
233\end{array}$} & \multirow{3}{*}{$\begin{array}{c}\% \% \\
54.4 \\
47.6\end{array}$} \\
\hline & Male & & \\
\hline sex & Female & & \\
\hline \multirow{8}{*}{ Age (years) } & $18-29$ & 4 & 0.8 \\
\hline & $30-39$ & 5 & 1.0 \\
\hline & $40-49$ & 19 & 3.9 \\
\hline & $50-59$ & 34 & 7.0 \\
\hline & $60-69$ & 75 & 15.3 \\
\hline & $70-79$ & 163 & 33.3 \\
\hline & $80-89$ & 161 & 32.9 \\
\hline & $\geq 90$ & 28 & 5.7 \\
\hline \multirow{9}{*}{ Speciality } & Cardiology/pneumology & 257 & 52.6 \\
\hline & Visceral/thoracic surgery & 93 & 19.0 \\
\hline & Gastroenterology & 39 & 8.0 \\
\hline & Vascular surgery & 31 & 6.3 \\
\hline & Trauma/orthopaedic surgery & 26 & 5.3 \\
\hline & Neurology & 22 & 4.5 \\
\hline & Hemato oncology & 19 & 3.9 \\
\hline & Gynaecology & 1 & 0.2 \\
\hline & Paediatrics & 1 & 0.2 \\
\hline \multirow{3}{*}{ Ward } & Medical ICU & 225 & 46.0 \\
\hline & Surgical ICU/IMC & 179 & 36.6 \\
\hline & Medical IMC & 85 & 17.4 \\
\hline \multirow{7}{*}{ Religion } & Unknown & 245 & 50.1 \\
\hline & Protestant & 141 & 28.8 \\
\hline & Roman Catholic & 87 & 17.8 \\
\hline & Without religious affiliation & 5 & 1.0 \\
\hline & Jehovah’s witnesses & 4 & 0.8 \\
\hline & Muslim & 4 & 0.8 \\
\hline & Others & 3 & 0.6 \\
\hline \multirow{18}{*}{ Main diagnosis } & Cardiovascular & 135 & 27.6 \\
\hline & $\begin{array}{c}\text { Intensive care complex } \\
\text { treatment }\end{array}$ & 97 & 19.8 \\
\hline & Respiratory system & 61 & 12.4 \\
\hline & Gastrointestinal & 45 & 9.2 \\
\hline & Urology & 27 & 5.5 \\
\hline & Infectious, parasitic diseases & 26 & 5.3 \\
\hline & Hepatobiliar, pancreatic & 22 & 4.5 \\
\hline & Musculoskeletal & 22 & 4.5 \\
\hline & CNS & 21 & 4.3 \\
\hline & Hemato-oncology & 12 & 2.4 \\
\hline & Endocrinology & 8 & 1.6 \\
\hline & Dermatology & 3 & 0.6 \\
\hline & Severely, multiple injured & 3 & 0.6 \\
\hline & Others & 2 & 0.4 \\
\hline & Hematology & 2 & 0.4 \\
\hline & Eye & 1 & 0.2 \\
\hline & Gynaecology & 1 & 0.2 \\
\hline & Intoxication & 1 & 0.2 \\
\hline \multirow{7}{*}{ Weekday of death } & Monday & 76 & 15.5 \\
\hline & Tuesday & 71 & 14.5 \\
\hline & Wednesday & 68 & 13.9 \\
\hline & Thursday & 72 & 14.7 \\
\hline & Friday & 69 & 14.1 \\
\hline & Saturday & 71 & 14.5 \\
\hline & Sunday & 62 & 12.7 \\
\hline
\end{tabular}

TABle 1: Continued.

\begin{tabular}{lccc}
\hline \multicolumn{1}{c}{ Patients' characteristics } & $n$ & $\%$ \\
\hline & $0-4$ & 77 & 15.7 \\
Day-time/hour of & $4-8$ & 64 & 13.1 \\
death & $8-12$ & 81 & 16.6 \\
& $12-16$ & 75 & 15.3 \\
& $16-20$ & 92 & 18.8 \\
& $20-24$ & 100 & 20.4 \\
\hline & $0-9$ & 409 & 83.6 \\
Days in the IMC/ICU & $10-19$ & 52 & 10.6 \\
& $20-29$ & 12 & 2.5 \\
& $30-39$ & 7 & 1.4 \\
& $40-49$ & 4 & 0.8 \\
& $50-59$ & 2 & 0.4 \\
& $60-69$ & 2 & 0.4 \\
$70-79$ & 1 & 0.2 \\
\hline & 0 & 169 & 34.6 \\
& $1-99$ & 203 & 41.5 \\
& $100-199$ & 49 & 10.0 \\
& $200-299$ & 16 & 3.3 \\
& $300-399$ & 16 & 3.3 \\
& $400-499$ & 9 & 1.8 \\
& $500-599$ & 6 & 1.2 \\
& $600-699$ & 7 & 1.4 \\
& $700-799$ & 3 & 0.6 \\
& $800-899$ & 2 & 0.4 \\
& $900-999$ & 4 & 0.8 \\
& $\geq 1000$ & 5 & 1.0 \\
\hline
\end{tabular}

were large university hospitals [19]. Other studies investigating end-of-life decisions in German ICUs are from an University hospital, too [22, 23]. Because only 35 of 1942 hospitals in Germany are university hospitals [27], there is still too little known about end-of-life decisions in Germany.

In 2011/2012, we did not use a standardised documentation of therapy withholding/withdrawal. Only cases with clear documentation or unambiguous hints for withholding or withdrawal were classified as withheld or withdrawn. We might have missed cases of withholding/ withdrawal which were done in agreement with the patient and/or the family but not explicitly mentioned in the chart. The "advanced directives law" (enacted in Germany in September 2009 [28]) states that physicians as well as relatives are obliged to respect patients' wishes/preferences referring to medical therapies. In our study, only about $12 \%$ of patients had a written advance directive which is comparable to low rates reported in other studies [22, 23]. We suppose that, in most cases, end-of-life decisions are medical decisions which have been discussed with patients or relatives to respect patient's wishes.

Time intervals as time from ICU arrival to death or duration of ventilation are probably reasonably exact because they are extracted from $\mathrm{SAP}^{\circledR}$, checked by trained controllers and are the base for the refunding system in Germany. Unfortunately, due to paper-based documentation without exact time markers, an exact definition of withholding or withdrawal "time point" was not possible in 


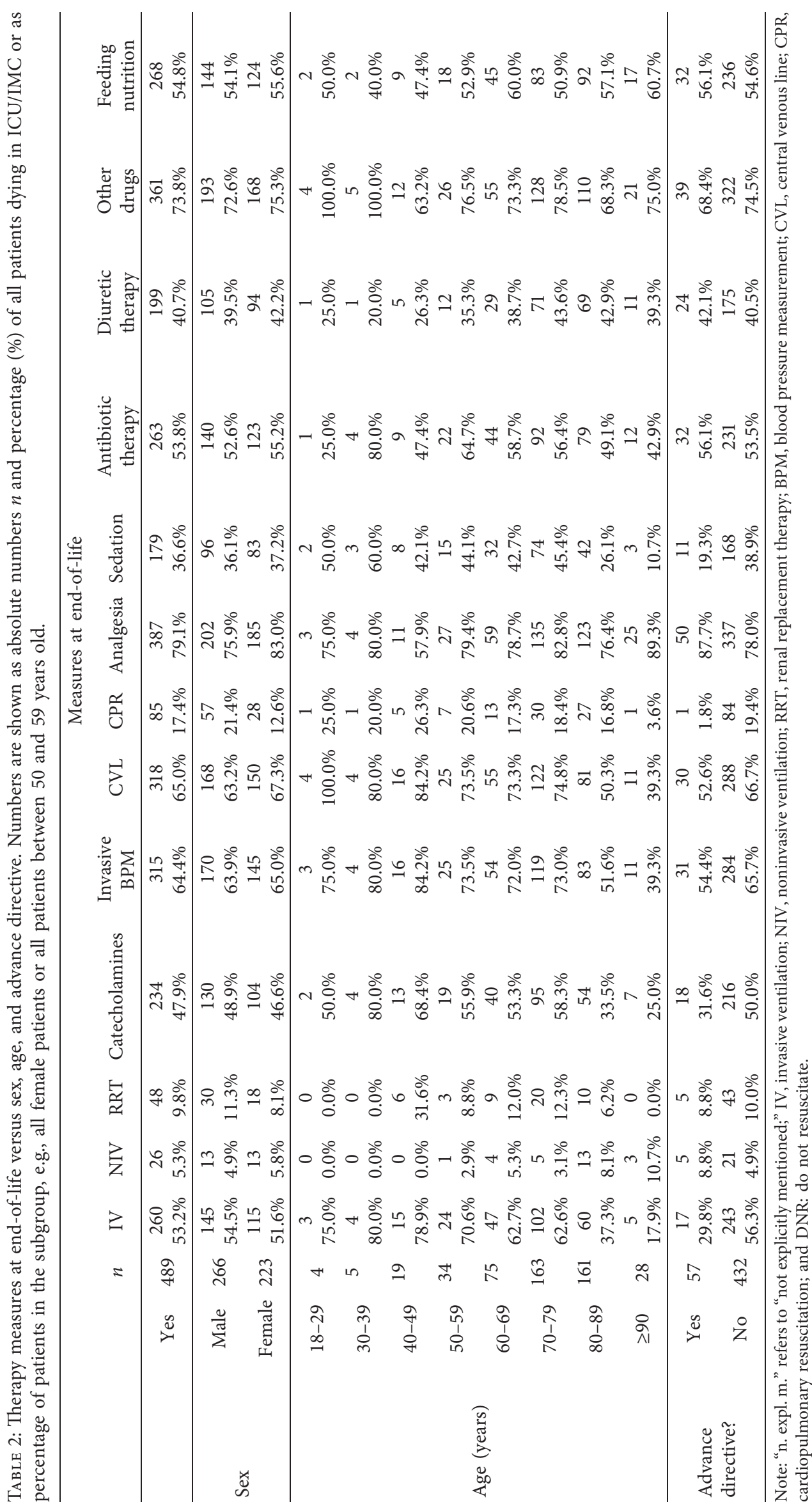


TABle 3: Therapy withholding at end-of-life versus sex, age and advance directive. Numbers are shown as absolute numbers $n$ and percentage (\%) of all patients dying in ICU/IMC or as percentage of patients in the subgroup, e.g., all female patients or all patients between 50 and 59 years old.

\begin{tabular}{|c|c|c|c|c|c|c|c|c|c|}
\hline & & \multirow[b]{2}{*}{$n$} & \multicolumn{7}{|c|}{ Therapy withholding? } \\
\hline & & & \multicolumn{2}{|c|}{ Withholding? } & IV & NIV & RRT & Catecholamines & DNR \\
\hline & \multirow{4}{*}{ Yes } & \multirow{4}{*}{489} & \multirow[b]{2}{*}{297} & \multirow[b]{2}{*}{ Yes } & 121 & 40 & 71 & 66 & 222 \\
\hline & & & & & $24.7 \%$ & $8.2 \%$ & $14.5 \%$ & $13.5 \%$ & $45.4 \%$ \\
\hline & & & \multirow{2}{*}{$60.7 \%$} & \multirow{2}{*}{ n. expl. m. } & 77 & 87 & 156 & 141 & 68 \\
\hline & & & & & $15.7 \%$ & $17.8 \%$ & $31.9 \%$ & $28.8 \%$ & $13.9 \%$ \\
\hline & \multirow{2}{*}{ No } & & 192 & & 291 & 362 & 262 & 282 & 199 \\
\hline & & & $39.3 \%$ & & $59.5 \%$ & $74.0 \%$ & $53.6 \%$ & $57.7 \%$ & $40.7 \%$ \\
\hline \multirow{8}{*}{ Sex } & \multirow{4}{*}{ Male } & \multirow{4}{*}{266} & \multirow{2}{*}{147} & \multirow{2}{*}{ Yes } & 58 & 19 & 36 & 32 & 113 \\
\hline & & & & & $21.8 \%$ & $7.1 \%$ & $13.5 \%$ & $12.0 \%$ & $42.5 \%$ \\
\hline & & & \multirow{2}{*}{$55.3 \%$} & $\mathrm{n}$ expl m & 40 & 44 & 75 & 68 & 30 \\
\hline & & & & n. expl. m. & $15.0 \%$ & $16.5 \%$ & $28.2 \%$ & $25.6 \%$ & $11.3 \%$ \\
\hline & & & & & 63 & 21 & 35 & 34 & 109 \\
\hline & Female & 223 & 150 & Yes & $28.3 \%$ & $9.4 \%$ & $15.7 \%$ & $15.2 \%$ & $48.9 \%$ \\
\hline & remale & 223 & & & 37 & 43 & 81 & 73 & 38 \\
\hline & & & $6 / .3 \%$ & n. expl. m. & $16.6 \%$ & $19.3 \%$ & $36.3 \%$ & $32.7 \%$ & $17.0 \%$ \\
\hline & & & & & 1 & 1 & 0 & 0 & 1 \\
\hline & $18-29$ & 4 & 1 & Yes & $25.0 \%$ & $25.0 \%$ & $0.0 \%$ & $0.0 \%$ & $25.0 \%$ \\
\hline & $18-29$ & 4 & $250 \%$ & $\mathrm{n}$ expl $\mathrm{m}$ & 0 & 0 & 1 & 1 & 0 \\
\hline & & & $25.0 \%$ & n. expl. m. & $0.0 \%$ & $0.0 \%$ & $25.0 \%$ & $25.0 \%$ & $0.0 \%$ \\
\hline & & & & & 0 & 0 & 0 & 0 & 1 \\
\hline & $30-39$ & 5 & 1 & Yes & $0.0 \%$ & $0.0 \%$ & $0.0 \%$ & $0.0 \%$ & $20.0 \%$ \\
\hline & $30-39$ & 3 & $20.0 \%$ & $\mathrm{n}$ expl m. & 1 & 1 & 1 & 1 & 0 \\
\hline & & & $20.0 \%$ & n. expl. m. & $20.0 \%$ & $20.0 \%$ & $20.0 \%$ & $20.0 \%$ & $0.0 \%$ \\
\hline & & & & & 2 & 0 & 2 & 2 & 6 \\
\hline & $40-49$ & 19 & 6 & Yes & $10.5 \%$ & $0.0 \%$ & $10.5 \%$ & $10.5 \%$ & $31.6 \%$ \\
\hline & $40-49$ & 19 & & n. expl.m. & 0 & 0 & 2 & 3 & 0 \\
\hline & & & $31.6 \%$ & n. expl. m. & $0.0 \%$ & $0.0 \%$ & $10.5 \%$ & $15.8 \%$ & $0.0 \%$ \\
\hline & & & & Yes & 2 & 0 & 2 & 4 & 10 \\
\hline & $50-59$ & 34 & 17 & Yes & $5.9 \%$ & $0.0 \%$ & $5.9 \%$ & $11.8 \%$ & $29.4 \%$ \\
\hline & $50-59$ & 34 & $500 \%$ & $\mathrm{n}$ expl m & 3 & 3 & 10 & 7 & 6 \\
\hline Age (years) & & & $50.0 \%$ & n. expl. m. & $8.8 \%$ & $8.8 \%$ & $29.4 \%$ & $20.6 \%$ & $17.6 \%$ \\
\hline Age (years) & & & 40 & Yes & 18 & 6 & 14 & 11 & 32 \\
\hline & $60-69$ & 75 & 40 & & $24.0 \%$ & $8.0 \%$ & $18.7 \%$ & $14.7 \%$ & $42.7 \%$ \\
\hline & $60-69$ & 75 & 53.30 & & 5 & 5 & 15 & 16 & 4 \\
\hline & & & $53.3 \%$ & n. expl. m. & $6.7 \%$ & $6.7 \%$ & $20.0 \%$ & $21.3 \%$ & $5.3 \%$ \\
\hline & & & 92 & Yes & 38 & 10 & 19 & 22 & 73 \\
\hline & $70-79$ & 163 & 92 & & $23.3 \%$ & $6.1 \%$ & $11.7 \%$ & $13.5 \%$ & $44.8 \%$ \\
\hline & $70-19$ & 163 & $56.4 \%$ & & 19 & 26 & 46 & 39 & 18 \\
\hline & & & $56.4 \%$ & n. expl. m. & $11.7 \%$ & $16.0 \%$ & $28.2 \%$ & $23.9 \%$ & $11.0 \%$ \\
\hline & & & 113 & Yes & 49 & 16 & 26 & 20 & 81 \\
\hline & $80-89$ & 161 & & & $30.4 \%$ & $9.9 \%$ & $16.1 \%$ & $12.4 \%$ & $50.3 \%$ \\
\hline & $80-89$ & 101 & & & 36 & 38 & 64 & 58 & 31 \\
\hline & & & $70.2 \%$ & n. expl. m. & $22.4 \%$ & $23.6 \%$ & $39.8 \%$ & $36.0 \%$ & $19.3 \%$ \\
\hline & & & 27 & Yes & 11 & 7 & 8 & 6 & 18 \\
\hline & $>90$ & 28 & & & $39.3 \%$ & $25.0 \%$ & $28.6 \%$ & $21.4 \%$ & $64.3 \%$ \\
\hline & $\geq 90$ & 28 & $964 \%$ & & 13 & 14 & 17 & 16 & 9 \\
\hline & & & $96.4 \%$ & n. expl. m. & $46.4 \%$ & $50.0 \%$ & $60.7 \%$ & $57.1 \%$ & $32.1 \%$ \\
\hline & & & & & 20 & 8 & 14 & 9 & 38 \\
\hline & & & 52 & Yes & $35.1 \%$ & $14.0 \%$ & $24.6 \%$ & $15.8 \%$ & $66.7 \%$ \\
\hline & Yes & b7 & $912 \%$ & $\mathrm{n}$ expl $\mathrm{m}$ & 18 & 21 & 31 & 27 & 13 \\
\hline & & & $91.2 \%$ & n. expl. m. & $31.6 \%$ & $36.8 \%$ & $54.4 \%$ & $47.4 \%$ & $22.8 \%$ \\
\hline Advance directive? & & & & & 101 & 32 & 57 & 57 & 184 \\
\hline & No & & 245 & Yes & $23.4 \%$ & $7.4 \%$ & $13.2 \%$ & $13.2 \%$ & $42.6 \%$ \\
\hline & No & 432 & $567 \%$ & $\mathrm{n}$ expl $\mathrm{m}$ & 59 & 66 & 125 & 114 & 55 \\
\hline & & & $50.1 \%$ & 11. expl. 111. & $13.7 \%$ & $15.3 \%$ & $28.9 \%$ & $26.4 \%$ & $12.7 \%$ \\
\hline
\end{tabular}


TABLE 4: Withdrawal of therapy versus sex, age and advance directive. Numbers are shown as absolute numbers $n$ and percentage (\%) of all patients dying in ICU/IMC or as percentage of patients in the subgroup, e.g. all female patients or all patients between 50 and 59 years old.

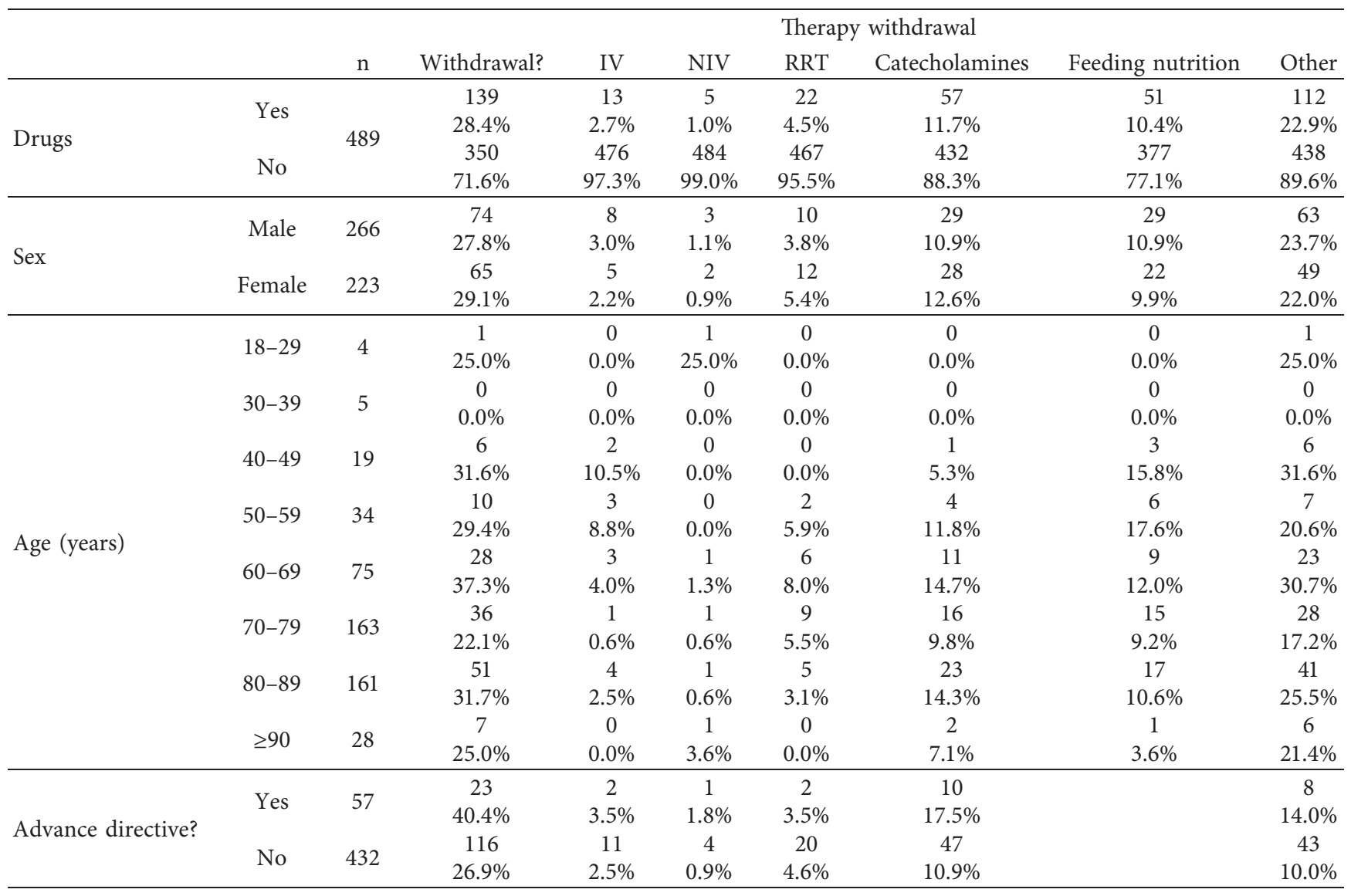

Note: "n. expl. m." refers to "not explicitly mentioned;" IV, invasive ventilation; NIV, noninvasive ventilation; RRT, renal replacement therapy; and DNR, do not resuscitate.

many cases. But the relevant time intervals for analysis of time intervals after withholding or withdrawal are probably days and not hours (Figure 2).

About $70 \%$ of deceased patients in our study are older than 70 years, and almost $40 \%$ are even older than 80 years which is comparable to other investigations $[19,22,23,26]$. It can be expected that the number of elderly patients in hospital and in ICUs will even further increase due to the demographic changes in the population [3]. Actually, there are more than 30 million people $\geq 65$ years in Germany, and it is expected that this number even increases within the next decades [3] It is likely that the patient's age might influence end-of-life decisions because intensivists might be less reluctant to limit or even withdraw a therapy in older patients. Most patients died due to cardiopulmonary problems (Table 1 ) which again is similar to results in other investigations [22, 23, 26, 29].

End-of-life decisions differ in patients with different religious affiliation $[19,30]$ and in medical staff with different religious backgrounds $[19,30]$. In most cases, the religious affiliation remained unknown because declaration of religious affiliation of hospital patients was voluntary. Surprisingly, the number of Muslims in our study is quite low because the Muslim population in Hanau is estimated to

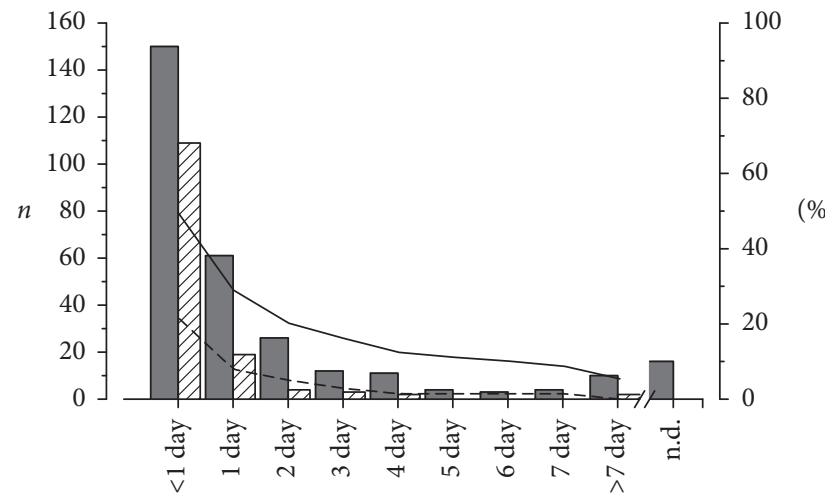

Time after limitation/withdrawal
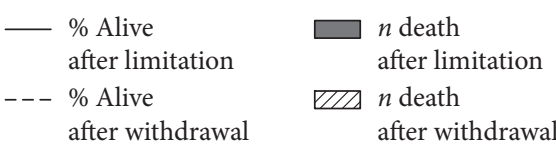

FIgURE 2: Time course after withholding or withdrawal of a lifesustaining therapy. The number of patients dying after withholding or withdrawal of a life-sustaining therapy is shown in bars. The percentage of patients who are still alive after withholding or withdrawal of therapy are plotted as lines. 
be about $20 \%$ of the overall population [31]. It cannot be excluded that many Muslim patients are "hidden" in the "unknown" group.

The even distribution of death might be due to the shift system which guarantees the presence of an ICU fellow in the ward and the presence of an intensive care consultant in the hospital 24 hours per day. Our colleagues from Berlin did not find a significant difference between weekdays and weekends, and they showed that most end-of-life decisions were done during normal working hours [22].

We could not analyse the causes of death in more detail. In Germany, there is no routine examination of patients dying in hospital by a coroner. Rarely, there is a postmortem section by a pathologist, and it cannot be excluded that the "cause of death" mentioned in the official death certificate is not always an exact diagnosis [32].

Therapy measures at end-of-life in our study are comparable but slightly different to that described in other studies $[19,22,23,26]$. About $60 \%$ of patients were ventilated compared to $88.6 \%$ in the ETHICUS investigation [19] and around $80 \%$ in the study from Charité Hospital [22]. Similarly, we saw lower rates of patients receiving catecholamine therapy $(47.9 \%)$ compared to around $60 \%$ in the other two studies $[19,22]$. The lower rates of these two invasive measures might be due to the inclusion of IMC patients in our study, whereas other studies investigated ICU patients only [19, 22, 23, 26]. We included IMC patients because sometimes there is smooth transition between ICU and IMC therapy [33].

Around $17 \%$ of our patients died under CPR or had CPR just before their death (Table 2). This might be a hint that these patients died under continued maximal therapy. On the other hand, we categorized three patients as "dying under CPR," although we found a "DNR" mark in their patients' charts. It is difficult to argue about the plausibility of CPR just by looking at the charts, but it is well known that many patients receive nonbeneficial treatment at the end-oflife [10]. Meanwhile, we introduced standard forms for endof-life decisions in our hospital [34] to reduce imprudent transfers of patients to the ICU in emergency situations.

Almost $80 \%$ of deceased patients received any kind of analgesia, and $37 \%$ got any kind of sedation drugs. This is reassuring but one-fifth of dying patients did not receive analgesia, and almost $2 / 3$ of dying patients did not get any sedation drug. We cannot say if patients without analgetics just did not have any pain or if it was forgotten to ask for pain and to subscribe an analgesic.

In about $60 \%$ of patients, we found withholding of at least one invasive measure (Table 3), and in about 30\% of patients, at least one measure was withdrawn (Table 4) which was in the range reported $[19,22,35]$. The more invasive the measure, the more likely was a withholding of its use. It was more likely that the less-invasive measures such as drugs and catecholamines were withdrawn than renal replacement therapy or invasive ventilation. It can only be speculated that physicians are still more reluctant to withdraw a therapy if it is more invasive and they expect a prompt correlation between withdrawal and death. We observed a tendency that invasive measures are more often used and less often withheldin younger patients. However, for patients under 40 years old, the absolute number for "therapy measures", and for patients under 60 years old, the absolute numbers for "therapy withholding" and "therapy withdrawal" are very low (Tables 3 and 4). It is likely that older patients might "get their chance" in the ICU, but doctors are more reluctant to initiate or to continue invasive measures.

The short time between withholding/withdrawal of therapy and death is expected because those therapy measures are-by definition-life sustaining. However, therapy is withheld/withdrawn just a few days before death, and we cannot exclude that invasive measures have already been applied to patients for too long [10].

Other investigators could show that early or regular involvement of a palliative care team member can reduce invasiveness of therapy in critically or terminally ill patients $[16,36-38]$. We try to implement principles of good palliative care in our daily intensive care [39], but currently we do not check regularly for palliative care or end-of-life issues when admitting a patient to the ICU. We interact closely with the ambulant palliative care team in Hanau, and many physicians of our team have been working in the palliative care team for six to twelve months.

\section{Conclusion}

Withholding and/or withdrawal of therapy preceded most deaths in our ICU/IMC. By trend, more invasive measures were used less often but more often withheld in older patients. Most patients died within two days after withholding or withdrawal of a life-sustaining therapy.

\section{Abbreviations}

ICU: Intensive care unit

IMC: Intermediate care unit

DRG: German diagnosis-related group

CPR: Cardiopulmonary resuscitation

IV: Invasive ventilation

NIV: Noninvasive ventilation

RRT: Renal replacement therapy

BPM: Blood pressure measurement

CVL: Central venous line

CPR: Cardiopulmonary resuscitation

DNR: Do not resuscitate.

\section{Data Availability}

The datasets used and/or analysed during the current study are available from the corresponding author upon reasonable request.

\section{Ethical Approval}

Ethical approval was given before analysing data by the Landesärztekammer Hessen, Germany (FF 131/2013, 23.01.2014).

\section{Conflicts of Interest}

The authors declare that they have no conflicts of interest. 


\section{Authors' Contributions}

EA and MG had the idea for the study, planned it, carried it out, and wrote the manuscript. MAW had the idea for the study and made substantial reviews. RR supported the study design and made substantial reviews.

\section{Acknowledgments}

The authors would like to thank Dr. M. Heinzel-Gutenbrunner (http://www.statistik-beratung.net) and Jonas Bienzeisler (University Hospital RWTH Aachen) for their support in data analysis and presentation.

\section{References}

[1] D. C. Angus, A. E. Barnato, W. T. Linde-Zwirble et al., "Use of intensive care at the end of life in the United States: an epidemiologic study*," Critical Care Medicine, vol. 32, no. 3, pp. 638-643, 2004.

[2] D. J. Lamas, R. L. Owens, R. N. Nace et al., "Opening the door," Critical Care Medicine, vol. 45, no. 4, pp. e357-e362, 2017.

[3] Federal Statistical Office, Elderly people in Germany and the European Union 2016-Ältere Menschen in Deutschland und der EU, Federal Statistical Office, Wiesbaden, Germany, 2016.

[4] K. Hillman, F. Athari, and R. Forero, "States worse than death," Current Opinion in Critical Care, vol. 24, no. 5, pp. 415-420, 2018.

[5] J. M. Garrett, R. P. Harris, J. K. Norburn, D. L. Patrick, and M. Danis, "Life-sustaining treatments during terminal illness," Journal of General Internal Medicine, vol. 8, no. 7, pp. 361-368, 1993.

[6] E. W. Ely, E. Azoulay, and C. L. Sprung, "Eight things we would never do regarding end-of-life care in the ICU," Intensive Care Medicine, vol. 45, no. 8, pp. 1116-1118, 2019.

[7] A. C. Mosenthal, P. A. Murphy, L. K. Barker, R. Lavery, A. Retano, and D. H. Livingston, "Changing the culture around end-of-life care in the trauma intensive care unit," The Journal of Trauma: Injury, Infection, and Critical Care, vol. 64, no. 6, pp. 1587-1593, 2008.

[8] G. Revon-Rivière, V. Pauly, K. Baumstarck et al., "High-intensity end-of-life care among children, adolescents, and young adults with cancer who die in the hospital: A population-based study from the French national hospital database," Cancer, vol. 125, no. 13, pp. 2300-2308, 2019.

[9] D. K. Heyland, D. E. Allan, G. Rocker, P. Dodek, D. Pichora, and A. Gafni, "Discussing prognosis with patients and their families near the end of life: impact on satisfaction with endof-life care," Open Medicine: A Peer-Reviewed, Independent, Open-Access Journal, vol. 3, no. 3, pp. e101-e110, 2009.

[10] M. Cardona-Morrell, J. Kim, R. Turner, M. Anstey, I. Mitchell, and K. Hillman, "Non-beneficial treatments in hospital at the end of life: a systematic review on extent of the problem," International Journal for Quality in Health Care, vol. 28, no. 4, pp. 456-469, 2016.

[11] B. Zhang, M. E. Nilsson, and H. G. Prigerson, "Factors important to patients' quality of life at the end of life," Archives of Internal Medicine, vol. 172, no. 15, pp. 1133-1142, 2012.

[12] M. Y. Rady and D. J. Johnson, "Admission to intensive care unit at the end-of-life: is it an informed decision?," Palliative Medicine, vol. 18, no. 8, pp. 705-711, 2004.
[13] O. Gajic, S. R. Ahmad, M. E. Wilson, and D. A. Kaufman, "Outcomes of critical illness," Current Opinion in Critical Care, vol. 24, no. 5, pp. 394-400, 2018.

[14] G. Neitzke, H. Burchardi, G. Duttge et al., "Grenzen der sinnhaftigkeit von intensivmedizin," Medizinische Klinik-Intensivmedizin und Notfallmedizin, vol. 111, no. 6, pp. 486-492, 2016.

[15] R. D. Truog, M. L. Campbell, J. R. Curtis et al., "Recommendations for end-of-life care in the intensive care unit: a consensus statement by the American college of critical care medicine," Critical Care Medicine, vol. 36, no. 3, pp. 953-963, 2008.

[16] C. Connolly, O. Miskolci, D. Phelan, and D. J. Buggy, "End-oflife in the ICU: moving from "withdrawal of care" to a palliative care, patient-centred approach," British Journal of Anaesthesia, vol. 117, no. 2, pp. 143-145, 2016.

[17] R. K. Mani, J. V. Divatia, R. Chawla et al., "Guidelines for endof-life and palliative care in Indian intensive care to units: ISCCM consensus ethical position statement," Indian Journal of Critical Care Medicine, vol. 17, no. 5, pp. 26-41, 2013.

[18] T. J. Prendergast, M. T. Claessens, and J. M. Luce, "A national survey of end-of-life care for critically ill patients," American Journal of Respiratory and Critical Care Medicine, vol. 158, no. 4, pp. 1163-1167, 1998.

[19] C. L. Sprung, S. L. Cohen, P. Sjokvist et al., "End-of-life practices in European intensive care units," JAMA, vol. 290, no. 6, pp. 790-797, 2003.

[20] C. S. Dos Anjos, R. M. C. Borges, A. C. Chaves et al., "Religion as a determining factor for invasive care among physicians in end-of-life patients," Supportive Care in Cancer, vol. 28, no. 2, pp. 525-529, 2019.

[21] C. L. Sprung, S. Carmel, P. Sjokvist et al., "Attitudes of European physicians, nurses, patients, and families regarding end-of-life decisions: the ETHICATT study," Intensive Care Medicine, vol. 33, no. 1, pp. 104-110, 2007.

[22] J. A. Graw, C. D. Spies, K.-D. Wernecke, and J.-P. Braun, "Managing end-of-life decision making in intensive care medicine-a perspective from charité hospital, Germany," PLoS One, vol. 7, no. 10, Article ID e46446, 2012.

[23] J. A. Graw, C. D. Spies, F. Kork, K.-D. Wernecke, and J.-P. Braun, "End-of-life decisions in intensive care medicineshared decision-making and intensive care unit length of stay," World Journal of Surgery, vol. 39, no. 3, pp. 644-651, 2015.

[24] S. P. Keenan, K. D. Busche, L. M. Chen, R. Esmail, K. J. Inman, and W. J. Sibbald, "Withdrawal and withholding of life support in the intensive care unit: a comparison of teaching and community hospitals," Critical Care Medicine, vol. 26, no. 2, pp. 245-251, 1998.

[25] Statistisches Bundesamt, Sterbefälle Deutschland 2013-2017, Statistisches Bundesamt, Wiesbaden, Germany, 2019, https:// www-genesis.destatis.de/genesis/online/logon?language=de\& sequenz=tabelleErgebnis\&selectionname $=12613-0003 \&$ zeitsch eiben $=5$.

[26] O. Lesieur, EPILAT study group, M. Leloup, F. Gonzalez, and M.-F. Mamzer, "Withholding or withdrawal of treatment under French rules: a study performed in 43 intensive care units," Annals of Intensive Care, vol. 5, no. 1, p. 56, 2015.

[27] Statistisches Mamzer, Gesundheit-Grunddaten der Krankenhäuser, Statistisches Bundesamt, Wiesbaden, Germany, 2017, https://www.destatis.de/DE/Themen/Gesellschaft-Umwelt/ Gesundheit/Krankenhaeuser/Publikationen/Downloads-Kranken haeuser/grunddaten-krankenhaeuser-2120611177004.html.

[28] U. Wiesing, R. J. Jox, H.-J. Hessler, and G. D. Borasio, "A new law on advance directives in Germany," Journal of Medical Ethics, vol. 36, no. 12, pp. 779-783, 2010. 
[29] C. L. Sprung, D. Annane, D. Keh et al., "Hydrocortisone therapy for patients with septic shock," New England Journal of Medicine, vol. 358, no. 2, pp. 111-124, 2008.

[30] J. Phua, G. M. Joynt, M. Nishimura et al., "Withholding and withdrawal of life-sustaining treatments in intensive care units in Asia," JAMA Internal Medicine, vol. 175, no. 3, pp. 363-371, 2015.

[31] de i. islam.de, 2019, http://www.islam.de/1144_print.php.

[32] F. Zack, A. Kaden, S. Riepenhausen, D. Rentsch, R. Kegler, and A. Büttner, "Fehler bei der Ausstellung der Todesbescheinigung," Rechtsmedizin, vol. 27, no. 6, pp. 516-527, 2017.

[33] S. A. Ridley, "Intermediate care possibilities, requirements and solutions," Anaesthesia, vol. 53, no. 7, pp. 654-664, 1998.

[34] M. Gruß and F. Salomon, "Autonomie und Fürsorge in der Intensivmedizin," Der Anaesthesist, vol. 65, no. 11, pp. 875$888,2016$.

[35] C. S. Hartog, F. Hoffmann, A. Mikolajetz et al., "Übertherapie und emotionale Erschöpfung in der "end-of-life care"," Der Anaesthesist, vol. 67, no. 11, pp. 850-858, 2018.

[36] G. Digwood, D. Lustbader, R. Pekmezaris et al., "The impact of a palliative care unit on mortality rate and length of stay for medical intensive care unit patients," Palliative and Supportive Care, vol. 9, no. 4, pp. 387-392, 2011.

[37] D. Lustbader, R. Pekmezaris, M. Frankenthaler et al., "Palliative medicine consultation impacts DNR designation and length of stay for terminal medical MICU patients," Palliative and Supportive Care, vol. 9, no. 4, pp. 401-406, 2011.

[38] M. S. Hua, G. Li, C. D. Blinderman, and H. Wunsch, "Estimates of the need for palliative care consultation across United States intensive care units using a trigger-based model," American Journal of Respiratory and Critical Care Medicine, vol. 189, no. 4, pp. 428-436, 2014.

[39] B. O'Neill and M. Fallon, "ABC of palliative care: principles of palliative care and pain control," $B M J$, vol. 315 , no. 7111, pp. 801-804, 1997. 